\title{
In Helicobacter pylori auto-inducer-2, but not LuxS/MccAB catalysed reverse transsulphuration, regulates motility through modulation of flagellar gene transcription
}

\author{
Feifei Shen ${ }^{1,2,6^{*}}$, Laura Hobley ${ }^{3}$, Neil Doherty ${ }^{1,2,7}$, John T Loh ${ }^{4}$, Timothy L Cover ${ }^{4}$, R Elizabeth Sockett ${ }^{3}$,
} Kim R Hardie ${ }^{1,5}$, John C Atherton ${ }^{1,2}$

\begin{abstract}
Background: LuXS may function as a metabolic enzyme or as the synthase of a quorum sensing signalling molecule, auto-inducer-2 (Al-2); hence, the mechanism underlying phenotypic changes upon luxS inactivation is not always clear. In Helicobacter pylori, we have recently shown that, rather than functioning in recycling methionine as in most bacteria, LuxS (along with newly-characterised MccA and MccB), synthesises cysteine via reverse transsulphuration. In this study, we investigated whether and how LuxS controls motility of H. pylori, specifically if it has its effects via luxS-required cysteine metabolism or via Al-2 synthesis only.

Results: We report that disruption of luxS renders $H$. pylori non-motile in soft agar and by microscopy, whereas disruption of $m c c A_{\mathrm{Hp}}$ or $m c c B_{\mathrm{Hp}}$ (other genes in the cysteine provision pathway) does not, implying that the lost phenotype is not due to disrupted cysteine provision. The motility defect of the $\Delta / u x S_{H p}$ mutant was complemented genetically by luxS $\mathrm{Hp}_{\mathrm{p}}$ and also by addition of in vitro synthesised $\mathrm{Al}-2$ or 4, 5-dihydroxy-2, 3-pentanedione (DPD, the precursor of Al-2). In contrast, exogenously added cysteine could not restore motility to the $\Delta / u x S_{H p}$ mutant, confirming that Al-2 synthesis, but not the metabolic effect of LuxS was important. Microscopy showed reduced number and length of flagella in the $\Delta / u x S_{H p}$ mutant. Immunoblotting identified decreased levels of FlaA and FlgE but not FlaB in the $\triangle /$ uxS $S_{\mathrm{Hp}}$ mutant, and RT-PCR showed that the expression of flaA, flgE, motA, motB, flhA and flil but not flaB was reduced. Addition of DPD but not cysteine to the $\triangle / u \times S_{H p}$ mutant restored flagellar gene transcription, and the number and length of flagella.
\end{abstract}

Conclusions: Our data show that as well as being a metabolic enzyme, H. pylori LuxS has an alternative role in regulation of motility by modulating flagellar transcripts and flagellar biosynthesis through production of the signalling molecule Al-2.

\section{Background}

Many bacteria release extra-cellular signalling molecules (auto-inducers) to perform intercellular communication. It is generally assumed that auto-inducers are employed to regulate aspects of bacterial behaviour in response to cell population density (so-called quorum sensing). This includes changes in the expression of genes crucial for bacterial survival or virulence $[1,2]$. Auto-inducer-2

\footnotetext{
* Correspondence: fayeshen316@msn.com

'Centre for Biomolecular Sciences, University of Nottingham, University Park, Nottingham NG7 2RD, UK

Full list of author information is available at the end of the article
}

(AI-2) production is widespread among bacterial species; its formation is catalysed by the enzyme LuxS [3]. Many Gram-positive and Gram-negative bacterial species possess LuxS, and in some it has been shown to catalyse AI-2 production and to control quorum sensing (QS). Good examples include Vibrio harveyi and Vibrio cholera, where AI-2 has been shown to regulate densitydependent bioluminescence and virulence factor production, respectively $[4,5] . l u x S$ inactivation has also been shown to cause phenotypic alterations such as biofilm formation, changes in motility, toxin production, and 
reduced colonisation in various experimental infection models [3,6].

In addition to its QS role, LuxS catalyses one of the steps of the activated methyl cycle (AMC). The AMC is a central metabolic pathway that generates the $S$-adenosylmethionine (SAM) required by methyltransferases allowing the widespread methylation of proteins and DNA needed for cell function. It recycles the toxic product of these reactions, $S$-adenosylhomocysteine $(S A H)$, to help provide the cell with sulphur-containing amino acids [7]. As part of the AMC, the Pfs enzyme, 5'-methylthioadenosine nucleosidase/S-adenosylhomocysteine nucleosidase converts $S A H$ to $S$-ribosylhomocysteine $(S R H)$ which is subsequently converted to homocysteine by LuxS. The precursor of AI-2, 4, 5dihydroxy-2, 3-pentanedione (DPD) is generated as a by-product of this reaction. Through a process of dehydration and spontaneous cyclisation, some or all of the DPD is rearranged into a cocktail of chemically related molecules known as AI-2, including 4-hydroxy-5methyl-3 $(2 H)$ furanone, $(2 R, 4 S)$-2-methyl-2, 3, 3, 4 -tetrahydroxy-tetrahydrofuran and furanosyl borate diester. These have been shown to function as signals of communication between bacteria $[3,8,9]$. In some organisms, the AMC is different. For example, in Pseudomonas aeruginosa, LuxS and Pfs are replaced by a single enzyme (SAH hydrolase) which converts $S A H$ to homocysteine in a one step reaction without the concomitant production of DPD [7].

Helicobacter pylori, a Gram-negative bacterium which causes peptic ulceration, gastric cancer and gastric mucosa-associated lymphoid tissue (MALT) lymphoma, contains a $\operatorname{luxS}$ homologue and produces AI-2 [10-12]. $l u x S_{\mathrm{Hp}}\left(\mathrm{HP} 0105_{26695}\right.$; JHP0097 ${ }_{\mathrm{Jg9}}$ ) is positioned next to

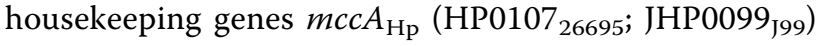
and $m c c B_{\mathrm{Hp}}\left(\mathrm{HPO106}_{26695}\right.$ JHP0098 $\left._{\mathrm{J} 99}\right)$ on the H. pylori chromosome, in a putative operon [13-15]. Data from our laboratory have demonstrated that the AMC of H. pylori is incomplete, and that $\mathrm{LuxS}_{\mathrm{Hp}}, \mathrm{MccA}_{\mathrm{Hp}}$ and $\mathrm{MccB}_{\mathrm{Hp}}$ constitute the sole cysteine biosynthetic pathway in this bacterium via a reverse transsulphuration pathway (RTSP) [15].

To date, the mechanisms underlying phenotypic changes exhibited as a result of $l u x S_{\mathrm{Hp}}$ inactivation remain elusive. Two $\Delta l u x S_{\mathrm{Hp}}$ mutants have been shown to form biofilms more efficiently than the parent strain, indicating a possible but counterintuitive role of $l u x S_{\mathrm{Hp}}$ in biofilm reduction [16]. A subsequent study demonstrated that $\Delta l u x S_{\mathrm{Hp}}$ mutants in two strains lost growth-phase-dependent regulation of the gene encoding the major flagellin FlaA, and that cell culture supernatant containing AI-2 could increase $f l a A$ transcription [17]. Studies by two independent groups looked at fitness of $\Delta l u x S_{\mathrm{Hp}}$ mutants in vivo using mouse and gerbil models, respectively $[18,19]$. The motility of $\Delta l u x S_{\mathrm{Hp}}$ mutants was diminished and bacterial fitness reduced in co-infection experiments. Restoration of $\operatorname{lux} S_{\mathrm{Hp}}$ by genetic complementation partially restored these phenotypes $[18,19]$. The authors argued that the decreased fitness in the $\Delta l u x S_{\mathrm{Hp}}$ mutant was most likely due to the disruption of the cycle of $S R H$ consumption and homocysteine synthesis and that AI-2 seemed unlikely to be a QS signal molecule [18]. More recently however, Rader et al. reported that $l u x S_{\mathrm{Hp}}$ disruption affected flagellar morphology in the absence of one of the transcriptional regulators $\left(\sigma^{28}\right.$, flgS or $\left.f l g M\right)$, and that this could be complemented upon the addition of DPD. They reported that loss of $l u x S_{\mathrm{Hp}}$ caused decreased transcription of the flagellar regulator $f l h A$, and that expression of $f l h A$ was induced by DPD [20]. This complementation through the addition of exogenous DPD resurrected the possibility of LuxSdependent signalling in $\mathrm{H}$. pylori.

There are several possible mechanisms whereby a motility defect could be associated with loss of $\operatorname{lux} S_{\mathrm{Hp}}$. Firstly, reduced flagellar structural gene transcription and related protein synthesis would lead to loss of flagella. Secondly, normal flagella structures may be synthesised in the $\Delta l u x S$ mutant but lack of a functional motor may prevent rotation. Thirdly, both motor and flagellum may be functional, but unable to respond to tactic signals, leading to aimless movement.

In this study, we set out to distinguish between the mechanisms underlying the alteration in motility of $\Delta l u x S_{\mathrm{Hp}}$ mutants, and to clarify whether this originated from a disruption of metabolism or QS. To do this, electron microscopy was employed to examine flagellar assembly and the levels of individual components of flagella were assessed at a transcriptional and translational level. Our demonstration here of the lack of motility defects in mutants disrupted in components of the RTSP other than LuxS, coupled to the inability of cysteine to complement the motility defect of the $\Delta l u x S_{\mathrm{Hp}}$ mutant, shows that disruption of cysteine biosynthesis is not the mechanism underlying the reduction in motility. In contrast, we show that exogenously added AI-2 (or DPD) influences motility via regulating flagellar gene transcription (and thus the number and length of flagella). This supports the existence of an additional role for LuxS in $H$. pylori as a signalling molecule synthase.

\section{Methods}

\section{Strains and growth culture conditions}

All strains used in this study are listed in Table 1. DH5 $\alpha$ was used in the production of proteins needed for AI-2 biosynthesis and cloning [21]. V. harveyi BB170 was used in the bioluminescence bioassay as a reporter strain [22]. E. coli strains were routinely grown in LuriaBertani (LB) (Bacto) broth or on agar plates at $37^{\circ} \mathrm{C}$. 
Table 1 Strains and plasmids used in this study

\begin{tabular}{|c|c|c|}
\hline Strains/Plasmids & Description & Reference \\
\hline \multicolumn{3}{|l|}{ Strains } \\
\hline \multicolumn{3}{|l|}{ Vibrio harveyi } \\
\hline BB170 & luxN :: Tn5 Al-1 sensor negative; Al-2 sensor positive & [43] \\
\hline \multicolumn{3}{|l|}{ Escherichia coli } \\
\hline $\mathrm{DH} 5 \alpha$ & 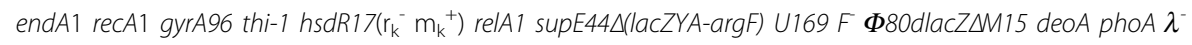 & {$[21]$} \\
\hline DH5 $\alpha$ LuxS & $\mathrm{DH} 5 \alpha$ containing the plasmid pProEx-luxS $S_{E C}$ & {$[8]$} \\
\hline $\mathrm{DH} 5 \alpha \mathrm{Pfs}$ & DH5 $\alpha$ containing the plasmid pProEx HT mtan & {$[8]$} \\
\hline \multicolumn{3}{|l|}{ Helicobacter pylori } \\
\hline J99 (ATCC700824) & Wild-type motile strain & {$[44]$} \\
\hline J99 $\Delta$ luxS & J99 derivative; $\Delta / \mathrm{uxS}:: \mathrm{km} ; \mathrm{Km}^{\mathrm{r}}$ & {$[15]$} \\
\hline J99 $/$ luxS-F & J99 derivative; $\triangle \mathrm{luxS}:: \mathrm{km}-\mathrm{sacB} ; \mathrm{Km}^{\mathrm{r}} \mathrm{Suc} \mathrm{s}^{\mathrm{s}}$ & This study \\
\hline J99 $\Delta / \mathrm{uxS}^{+}$ & 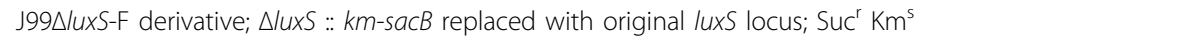 & This study \\
\hline$J 99 \triangle m c c A$ & J99 derivative; $\triangle m c c A:: \mathrm{km} ; \mathrm{Km}^{\mathrm{r}}$ & {$[15]$} \\
\hline J99 $\triangle m c c B$ & J99 derivative; $\triangle m c c B:: \mathrm{km} ; \mathrm{Km}^{\mathrm{r}}$ & {$[15]$} \\
\hline$J 99 \Delta f l h B$ & J99 derivative; $\triangle \mathrm{HP} 0770 \mathrm{Lys}^{13}$ to $\mathrm{Glu}^{347} ; \mathrm{Km}^{\mathrm{r}}$; non-motile & {$[24]$} \\
\hline CCUG $17874^{*}$ & Wild-type strain & {$[29]$} \\
\hline $17874 \triangle \mathrm{flaA}$ & 17874 derivative; $\Delta$ flaA $:: c_{c a t} \mathrm{Cm}^{r}$ & Paul OToole \\
\hline $17874 \triangle f l g E$ & 17874 derivative; $\Delta f l g E:: \mathrm{km} ; \mathrm{Km}^{\mathrm{r}}$ & [30] \\
\hline \multicolumn{3}{|l|}{ Plasmids } \\
\hline pGEMT & Commercial TA cloning vector; Ampr & Promega \\
\hline pGEMTluxSXN396 & pGEM-T with inserted 26695 luxS; $\Delta l u x S::$ km-sacB; Suc $\mathrm{Km}^{r}$ & {$[17]$} \\
\hline pGEMTluxS & PGEM-T with inserted full-length luxS fragment & This study \\
\hline pProEx-luxS EC & pProEX HT containing the luxS gene of E. coli MG1655 & {$[8]$} \\
\hline pProEx HT mtan & PProEX HT containing the pfs gene of E. coli & {$[8]$} \\
\hline
\end{tabular}

* CCUG 17874 is identical to the type strain NCTC 11637, isolated by B. J. Marshall at Royal Perth Hospital, May 1982 [29].

$V$. harveyi was grown in $\mathrm{LB}$ or $\mathrm{AB}$ medium [23] at $30^{\circ} \mathrm{C}$, also under normal atmospheric conditions. $H$. pylori strains were routinely grown and maintained on Columbia blood agar plates (No.2, with $5 \%[\mathrm{v} / \mathrm{v}]$ horse blood; Oxoid) or grown in Brucella broth (BB) (Bacto) containing $7 \%(\mathrm{v} / \mathrm{v})$ fetal bovine serum (Gibco). H. pylori $\mathrm{J} 99$ was incubated at $37{ }^{\circ} \mathrm{C}$ for $24 \mathrm{~h}$ to $72 \mathrm{~h}$ as required in a MG500 VAIN-cabinet (Don Whitley Scientific) in an atmosphere of $5 \% \mathrm{CO}_{2}, 86 \% \mathrm{~N}_{2}$, and $6 \% \mathrm{O}_{2}$ (all v/v). For motility experiments the method of Wand et al. [24] was used to achieve motile cultures for analysis, see below. Antibiotics were used at the following concentrations: ampicillin at $100 \mu \mathrm{g} / \mathrm{ml}$, kanamycin at $30 \mu \mathrm{g} / \mathrm{ml}$.

\section{Molecular biology methods}

Preparation of plasmid DNA, DNA ligation, gel electrophoresis and transformation of $E$. coli strains were performed in accordance with standard methods [25]. All PCRs were performed with Taq DNA polymerase (Roche Diagnostics, Lewes, UK). TA cloning was carried out using the pGEM-T vector system (Promega, Madison, WI). Plasmid DNA was extracted using the
QIAquick spin miniprep kit (QIAGEN, UK). DNA fragments were purified from agarose gel using a QIAquick gel extraction kit (QIAquick, UK) according to the manufacturer's instruction. H. pylori genomic DNA was isolated as described previously [26]. DNA sequencing was conducted using standard fluorescent dye terminator chemistries, and analysis performed using the Applied Biosystems 3730 DNA Analyzer system (Geneservice, Cambridge, UK, Applied Biosystems Inc, Foster City, CA.). Results were analysed using the Bioedit software suite [27].

\section{Construction of the complemented $\Delta / u x S^{+}$strain}

$H$. pylori 199 wild-type was transformed with the plasmid pGEMTluxSXN396 containing a $k m-s a c B$ construct encoding kanamycin resistance $\left(\mathrm{Km}^{\mathrm{r}}\right)$ and $(5 \%)$ sucrose sensitivity $\left(\mathrm{Suc}^{\mathrm{s}}\right)$ [17]. Disruption of the chromosomal luxS gene was accomplished by natural transformation, allelic exchange, and screening for kanamycin-resistance as previously described [15], resulting in the $099 \Delta l u x S$ mutant strain. The presence of the $k m$-sacB cassette was verified by amplifying fragments of $H$. pylori chromosomal DNA 
using primers luxS-F/luxS-R (forward, 5'>GTG GCT TTA GCG GGA TGT TTT<3'; reverse, 5'>GCGA ACA AAT CCC CGC TG<3') and DNA sequencing. The J99 $\Delta l u x S$ was then transformed with plasmid pGEMTluxS (encoding wild-type $\operatorname{luxS}$ ), and transformants in which $k m$-sacB had been replaced with the introduced original $\operatorname{luxS}$ locus were selected for sucrose resistance on medium containing $5 \%$ sucrose and screened for kanamycin sensitivity. The presence of the original $\operatorname{luxS}$ gene was verified by amplifying fragments on H. pylori chromosomal DNA using primers $l u x S-F / l u x S-R$ and DNA sequencing.

\section{Bacterial growth curves and $V$. harveyi bioluminescence assay}

Bacterial broth cultures were started from a blood agar plate culture, diluted to an $\mathrm{OD}_{600 \mathrm{~nm}}$ of 0.05 in fresh $\mathrm{BB}$ medium, and grown at $37^{\circ} \mathrm{C}$ in a VAIN-cabinet with shaking. $\mathrm{OD}_{600 \mathrm{~nm}}$ measurements were taken at the $6 \mathrm{~h}$, $24 \mathrm{~h}, 48 \mathrm{~h}$ and $72 \mathrm{~h}$ time points, and at the same time cell suspensions were harvested and filtered through a $0.2 \mu \mathrm{m}$ pore size filter. The AI-2 activity in cell free supernatants (CFS) was tested as previously described using the $V$. harveyi reporter strain BB170 [9,22]. Briefly, an overnight $V$. harveyi culture was diluted 1:2500 in fresh $A B$ medium [23]. CFS samples were diluted 1:10 in the $\mathrm{AB}$ medium containing BB170 into the 96 well bioluminescence plates to give a final volume of $200 \mu \mathrm{l}$ and were incubated at $30^{\circ} \mathrm{C}$. The bioluminescence and optical density were determined at $30 \mathrm{~min}$ intervals for at least $8 \mathrm{~h}$ using a luminometer (Anthos Labtech LUCY 1.0). AI-2 activity alterations in bioluminescence were expressed as induction ( $\mathrm{n}$-fold) over the negative control.

\section{Motility assay}

Plate motility assay of $\mathrm{H}$. pylori was performed in Brucella broth medium (BD Biosciences), supplemented with 7\% (v/v) fetal bovine serum (Gibco), 0.35\%-0.45\% (w/v) agar (No.1, Oxoid) and the indicator, $40 \mu \mathrm{g} / \mathrm{ml}$ triphenyl tetrazolium chloride (Sigma, UK). Inclusion of this indicator made it easier to see the small recombinant colonies. Plates were seeded with $5 \mu \mathrm{l} \mathrm{H}$. pylori liquid culture (forming a circle with $3 \mathrm{~mm}$ diameter) standardised to an $\mathrm{OD}_{600 \mathrm{~nm}}$ of 1.0 and were incubated at $37^{\circ} \mathrm{C}$ for up to 7 days under the conditions described above. The motility halos were recorded using a digital camera and the area of each halo was measured using a GS-800 Calibrated Densitometer (Biorad).

Motility analysis was also carried out by direct observation under phase-contrast microscopy using a Nikon Eclipse E600 after cells were grown in co-culture conditions as used by Wand et al. [24]. Briefly, co-cultures of H. pylori-human gastric adenocarcinoma (AGS) cells were prepared (described below). After $24 \mathrm{~h}, 10 \mu \mathrm{l}$ culture was placed onto a microscope slide and covered with a coverslip and freely-motile $H$. pylori cells were analysed under the microscope.

\section{Plate motility bioassay using chemically defined media (CDM)}

The liquid chemically defined media were prepared as previously described $[15,28] .60 \mathrm{ml}$ of sterile chemically defined media were added to $40 \mathrm{ml}$ of molten $1 \%$ Oxoid No. 1 agar base to make $0.4 \%$ semi-solid chemically defined agar. Cysteine supplemented plates (CSP) were made by adding cysteine to the molten agar, shortly before it set. The final concentration of cysteine was $1.0 \mathrm{mM}$, which was non-limiting for $H$. pylori growth. The centre of each plate was seeded with one-day incubated $H$. pylori cells and was incubated for 5 days under the conditions described above. The motility halos were recorded using a digital camera and the area of each halo was measured using a GS-800 Calibrated Densitometer (Biorad).

\section{Motility assay with Al-2 complementation}

AI-2 was synthesised enzymatically as described previously using purified proteins $\operatorname{LuxS}_{E \text {. coli }}$ and $\mathrm{Pfs}_{E .}$ coli [8]. For complementation of the $\Delta l u x S_{\mathrm{Hp}}$ motility phenotype, soft motility agar plates $(0.4 \% \mathrm{w} / \mathrm{v})$ were made as previously described. Bioluminescence activity of the AI-2 product was quantified using the $V$. harveyi bioassay and compared to CFS from $H$. pylori wild-type broth culture standardised to an $\mathrm{OD}_{600 \mathrm{~nm}}$ of 1.0 at the time point in the growth curve that maximal AI-2 activity was measured. 1/400 diluted in vitro synthesised AI-2 product shows the same level of bioluminescence as seen in the $H$. pylori wild-type CFS in the $V$. harveyi bioassay. Therefore, in the complementation experiment AI-2 was added to motility plates to a final concentration of $0.25 \%(\mathrm{v} / \mathrm{v}) .24 \mathrm{~h} H$. pylori cultures were seeded individually onto the centre of each motility plate and incubated for 5 days. The area of outward migration was recorded with a digital camera and measured using a GS-800 Calibrated Densitometer (Biorad).

\section{Tissue culture and bacterial co-culture}

All chemicals were obtained from Gibco, UK. AGS cells were grown in nutrient mixture Ham's F-12 supplemented with L-glutamine $(200 \mathrm{mM})$ and fetal bovine serum (Gibco) $(10 \% \mathrm{v} / \mathrm{v})$ in a $37^{\circ} \mathrm{C}$ incubator containing $5 \%$ $\mathrm{CO}_{2}$. After cells had grown to confluency, a 1 in 5 or 1 in 8 dilution was added to a $75 \mathrm{~cm}^{2}$ flask containing fresh media mix and incubated in the same conditions as before to allow cells to re-grow to confluency.

AGS cells were counted using the trypan $(0.35 \% \mathrm{v} / \mathrm{v})$ blue dye method. Cells were seeded at a density of $1 \times 10^{5}$ cells $/ \mathrm{ml}$ into 6 well plates and grown to $80 \%$ confluency. 
The cell-media mix was removed and replaced with $2 \mathrm{ml}$ fresh F-12 media. Plates were inoculated with $24 \mathrm{~h}$ H. pylori liquid cultures standardised to an $\mathrm{OD}_{600 \mathrm{~nm}}$ of 0.1 and incubated for one day in a microaerobic environment. Bacterial cells were then analysed using a phasecontrast Nikon Eclipse E600 microscope and electron microscopy.

\section{Electron microscopy (EM)}

H. pylori cells were pre-grown as described above for motility analysis. $15 \mu \mathrm{l}$ of culture was allowed to settle on a carbon formvar grid (Agar Scientific) for $1 \mathrm{~min}$. The suspension was removed and the grid washed by addition of $15 \mu \mathrm{l}$ of Phosphate Buffered Saline (PBS) for an additional minute. This was removed and the cells stained with $0.5 \%$ Phospho-tungstic acid (PTA) $\mathrm{pH} 7.0$ for $1 \mathrm{~min}$. Grids were examined and pictures taken using a JEOL JEM1010 Transmission Electron Microscope. We quantified changes, rounding to the nearest $5 \%$ and quote means \pm SD. Essentially, three groups of H. pylori cell samples prepared on different dates were examined. Each group of samples contained wild-type, $\Delta l u x S$ and $\Delta l u x S^{+}$cells treated and not treated with DPD. For each group, $100 \mathrm{H}$. pylori cells from each culture sample were examined.

\section{Cysteine and DPD complementation experiments}

Cysteine from Sigma products was dissolved in distilled water according to the manufacturer's recommendation. Synthetic DPD was purchased from Omm Scientific Inc. DPD (AI-2) activity was quantified with the bioluminescence bioassay and compared to wild-type $H$. pylori grown to an $\mathrm{OD}_{600 \mathrm{~nm}}$ of 1.0, at which maximal AI-2 activity was obtained. To test for complementation of motility, DPD (at a physiological concentration of 150 $\mu \mathrm{M})$ and non-limiting cysteine $(1.0 \mathrm{mM})$ were added individually to bacteria-AGS cell co-cultures. DPD was added after $10 \mathrm{~h}$ of incubation and once again after $18 \mathrm{~h}$ of incubation. Cysteine was added from the beginning of incubation. Bacterial motility and cells were observed and visualized by phase-contrast microscope and EM, respectively. For gene transcription studies, DPD $(150 \mu \mathrm{M})$ and cysteine $(1.0 \mathrm{mM})$ were also added (in the same way) individually to $H$. pylori liquid cultures of different genotypes. After $24 \mathrm{~h}$, RNA was extracted and the transcript levels of genes of interest were measured.

\section{Protein electrophoresis and western blotting}

H. pylori wild-type, its $\Delta l u x S_{\mathrm{Hp}}$ mutant, the complemented $\Delta l u x S_{\mathrm{Hp}}{ }^{+}$mutant and controls (H. pylori wild-type 17874 [29], and derived mutants $\triangle$ flaA (a kind gift from Paul O'Toole) and $\Delta f l g E$ [30]) were grown in Brucella broth at $37^{\circ} \mathrm{C}$ for up to $24 \mathrm{~h}$, at which point high levels of AI-2 activity were detected. To exclude global differences in protein production between strains, we corrected our loading for numbers of bacteria rather than for total protein levels. To do this, $24 \mathrm{~h}$ liquid (Brucella broth) culture of each strain was adjusted to $\mathrm{OD}_{600 \mathrm{~nm}}$ of 1.0. A $500 \mu \mathrm{l}$ cell sample of each strain was then centrifuged at $5500 \mathrm{rpm}$ for $1 \mathrm{~min}$. Culture supernatants were removed and cell pellets were fully resuspended in $1 \mathrm{ml}$ sterile PBS. $100 \mu \mathrm{l}$ protein sample was collected. The same volume of $2 \times$ sample buffer was added and boiled for $10 \mathrm{~min}$. SDS-polyacrylamide gel electrophoresis (SDS-PAGE) and subsequent immunoblotting were carried out as described previously under standard conditions [25]. The gel contained $10 \%$ acrylamide. $4 \mu \mathrm{l}$ protein stock from each strain sample was loaded into each well of the SDS-PAGE gel. For immunoblotting, proteins were transferred from SDS-PAGE gels to nitrocellulose paper by the methanol Tris-glycine system described by Towbin et al. [31]. To see whether similar amounts of protein were loaded using our methodology, membranes were inspected following Ponceau red staining prior to immunoblotting; protein levels appeared similar on each membrane by inspection. The blots were incubated with rabbit polyclonal antibodies against $H$. pylori flagellin and hook protein (a generous gift from Paul O'Toole) [32]. Bound antibodies were detected using secondary anti-rabbit IgG alkaline phosphatase conjugate antibody (Sigma, UK). The blots were developed using the BCIP/NBT substrate system (Dako, UK). The quantitative scan of the protein bands was performed using a GS-800 Calibrated Densitometer (Biorad). The reflective density (RD) of each protein band was measured using the Quantity One 4.6.5 software (Biorad).

\section{RNA extraction and transcription analysis}

RNA was isolated from $H$. pylori cells grown in BB medium for $24 \mathrm{~h}$. Cultures were treated with RNA protection reagent (QIAGEN, UK) and RNA was extracted using RNeasy mini kit (QIAGEN, UK). Contaminating genomic DNA was removed using a DNA free kit (Ambion). Synthesis of cDNA was performed using Ominiscript RT kit (QIAGEN, UK) and random hexamers (Roche, Germany). Quantitation of transcripts of selected genes of interest was accomplished by quantitative reverse transcription-PCRs (qRT-PCRs) using Rotor-gene 3000. Primers utilised in RT-PCRs are listed in Table 2. All RT-PCR reaction mixtures contained $12.5 \mu \mathrm{l}$ of SYBR Green Mix (QIAGEN, UK), $5 \mu \mathrm{l}$ of gene specific primers, $2 \mu \mathrm{l} \mathrm{cDNA}$ template (cDNA was diluted 10 -fold prior to adding into the RT-PCR reactions) and RNase free water to a final volume of $25 \mu \mathrm{l}$. The amplification program was $95^{\circ} \mathrm{C}$ for $15 \mathrm{~min}$, followed by 35 cycles of $95^{\circ} \mathrm{C}$ for $15 \mathrm{sec}, 56^{\circ} \mathrm{C}$ for $60 \mathrm{sec}$, and $72^{\circ} \mathrm{C}$ for $30 \mathrm{sec}$. All samples, including the 
Table 2 Primers utilised in quantitative RT-PCR

\begin{tabular}{lc}
\hline Primers & Sequence $\mathbf{( 5}^{\prime}$ - $\mathbf{3}^{\prime} \mathbf{)}$ \\
\hline $165 \_F$ & CGA TGA AGC TTC TAG CTT GC \\
$165 \_R$ & ATA GGA CAT AGG CTG ATC TC \\
flaAF & CAG GTT CGT ATC GCT ACA GGC \\
flaAR & ATC ACT TCT GCT AAC ACG CCG \\
flaBF & ACT GGG ATT GGG GCG TTA \\
flaBR & TCA ACC TCC CGTCAG CGT C \\
flgEF & GCT CAG GCA CGA TCA CTC TAA \\
flgER & AAC GCC ATG AAA GGT CTT AAT AC \\
flhAF & TCA TTG GAG GGT TTT TAG TGG \\
flhAR & GGT GCG AGT GGC GAC AAT \\
motAF & TGA GTT TAG AGG GGC GAG TG \\
motAR & CCA GTA ATG AGC GGC ACC \\
motBF & TTC AGG GAA AGA AGA AGA GCA A \\
motBR & TCA AAC AGC AAA CTA GAG AAA A \\
flifF & ACG AGC GAT GAT AGC CCT TTA \\
flilR & ACC GAT TTC TCT TTG AGC CAT \\
ureAF & GAT GAT GTG ATG GAT GGT GTG G \\
ureAR & TAA GAA CAA CTC ACC AGG AAC C \\
\hline
\end{tabular}

controls (16 $S$ rRNA and no-template), were run in triplicate. Transcript levels of each gene were normalised to the $16 S$ rRNA in each sample. The relative quantity of transcription of each gene was obtained using Pfaffl's analytical methodology.

\section{Statistics}

Statistical analysis was by Student's $t$ test.

\section{Results}

The $H$. pylori $\Delta$ luxS mutant lost the ability to produce Al-2 while the wild-type, $\Delta m c c A_{\mathrm{Hp}}$ and $\Delta m c c B_{\mathrm{Hp}}$ mutants did not

Our previous study has demonstrated that $\operatorname{lux} S_{\mathrm{Hp}}$, $m c c A_{\mathrm{Hp}}$ and $m c c B_{\mathrm{Hp}}$ genes comprise a reverse transulphuration pathway in $H$. pylori, which is the sole cysteine biosynthesis pathway [15]. We then wanted to determine whether these mutants in a motile strain of H. pylori, J99, would be useful in differentiating whether $H$. pylori motility was affected by $\operatorname{luxS}$ associated AI-2 production or by cysteine provision. Firstly, we needed to establish whether mutations in $m c c_{\mathrm{Hp}}$ genes in our candidate motile strain $\mathrm{J} 99$ changed expression of $\operatorname{luxS} S_{\mathrm{Hp}}$ and AI-2 biosynthesis. To do this, H. pylori $\mathrm{J99}$ wild-type and derived $\Delta m c c A_{\mathrm{Hp}}, \Delta m c c B_{\mathrm{Hp}}$, and $\Delta l u x S_{\mathrm{Hp}}$ mutants were grown in Brucella broth containing serum $(10 \% \mathrm{v} / \mathrm{v})$. Once they reached logarithmic growth phase, AI-2 activity in the culture supernatant was measured using the $V$. harveyi AI-2 bioassay previously described $[4,8]$. As expected, the wild-type produced AI-2 in a growth dependent manner, with AI-2 accumulating during the late logarithmic phase, and reaching maximal levels in the stationary phase. During stationary phase, AI-2 levels decreased and were almost undetectable by $72 \mathrm{~h}$. Similar data were obtained with $\Delta m c c A_{\mathrm{Hp}}$ and $\Delta m c c B_{\mathrm{Hp}}$ mutants, despite the fact that the $\Delta m c c B_{\mathrm{Hp}}$ mutant grew slightly less well than the other mutants and the wild-type. The $\Delta l u x S_{\mathrm{Hp}}$ mutant, unlike the wildtype and the other two mutants, yielded almost undetectable levels of bioluminescence at each time point, indicating that the production of AI-2 is $\operatorname{lux} S_{\mathrm{Hp}}$-dependent and that insertion of a kanamycin cassette (aphA3) into $m c c A_{\mathrm{Hp}}$ and $m c c B_{\mathrm{Hp}}$ did not affect expression of the downstream gene $\operatorname{lux} S_{\mathrm{Hp}}$ (Figure. 1A).

\section{Deletion of luxS $S_{\mathrm{Hp}}$ abolishes motility while the $\Delta m c c A_{\mathrm{Hp}}$ and $\Delta m c c B_{\mathrm{Hp}}$ mutants remained motile}

To investigate whether motility of $H$. pylori was affected by cysteine biosynthesis, we first compared the motility of $H$. pylori wild-type with $\Delta l u x S_{\mathrm{Hp}}, \Delta m c c A_{\mathrm{Hp}}$ and $\Delta m c c B_{\mathrm{Hp}}$ mutants. To do this, a $24 \mathrm{~h}$ liquid culture of each strain was spotted onto each quarter of a semisolid agar plate and incubated for up to 7 days. The resulting motility halo areas were quantified after 3, 5 and 7 days of incubation. Halo areas that surrounded the wild-type, $\Delta m c c A_{\mathrm{Hp}}$ and $\Delta m c c B_{\mathrm{Hp}}$ strains kept increasing during continuous incubation, although the $\Delta m c c A_{\mathrm{Hp}}$ strain was slightly delayed in comparison to the others. After 7 days of culture, the $\Delta l u x S_{\mathrm{Hp}}$ mutant remained almost non-motile and produced a significantly $(p<0.001)$ reduced motility halo compared to wild-type, $\Delta m c c A_{\mathrm{Hp}}$ and $\Delta m c c B_{\mathrm{Hp}}$ strains in 3 independent repeat experiments (Figure. $1 \mathrm{~B}$ ). After 7 days, the wild-type, $\Delta m c c A_{\mathrm{Hp}}$ and $\Delta m c c B_{\mathrm{Hp}}$ mutants produced halos of (mean $\pm \mathrm{SD}$ ) $8.5 \pm 0.6 \mathrm{~mm}, n=4 ; 5.6 \pm 0.9$ $\mathrm{mm}, n=4$; and $7.8 \pm 0.6 \mathrm{~mm}, n=4$ increases in diameter, respectively, all significantly greater than the $\Delta l u x S_{\mathrm{Hp}}$ mutant which produced a halo size of $1.1 \pm 0.1$ $\mathrm{mm}, n=4$. These results revealed that the reduction in motility was likely a result peculiar to $l u x S_{\mathrm{Hp}}$ mutation rather than due to disruption of cysteine biosynthesis.

\section{Genetic complementation or exogenous $\mathrm{Al}-2$ can restore the motility defect of the $\Delta l u x S_{\mathrm{Hp}}$ mutant, but exogenous cysteine addition cannot}

To rule out the possibility that second site mutations in the $\Delta l u x S_{\mathrm{Hp}}$ mutant were inhibiting motility, genetic complementation was performed to create the $\Delta l u x S_{\mathrm{Hp}}{ }^{+}$ strain (see Materials and Methods). The non-motile $\triangle f l h B$ mutant was used as a negative control [24]. $24 \mathrm{~h}$ cultures of wild-type, $\Delta l u x S_{\mathrm{Hp}}, \Delta l u x S_{\mathrm{Hp}}{ }^{+}$and $\Delta f l h B_{\mathrm{Hp}}$ strains grown in Brucella broth were individually spotted onto normal motility plates. After 5 days of incubation, the mean halo diameter of the $\Delta l u x S_{\mathrm{Hp}}{ }^{+}$strain was $6.9 \pm 0.2 \mathrm{~mm}, n=4$, which was slightly larger than that of the wild-type $(4.7 \pm 0.7 \mathrm{~mm}, n=4)$. The $\Delta l u x S_{\mathrm{Hp}}$ 


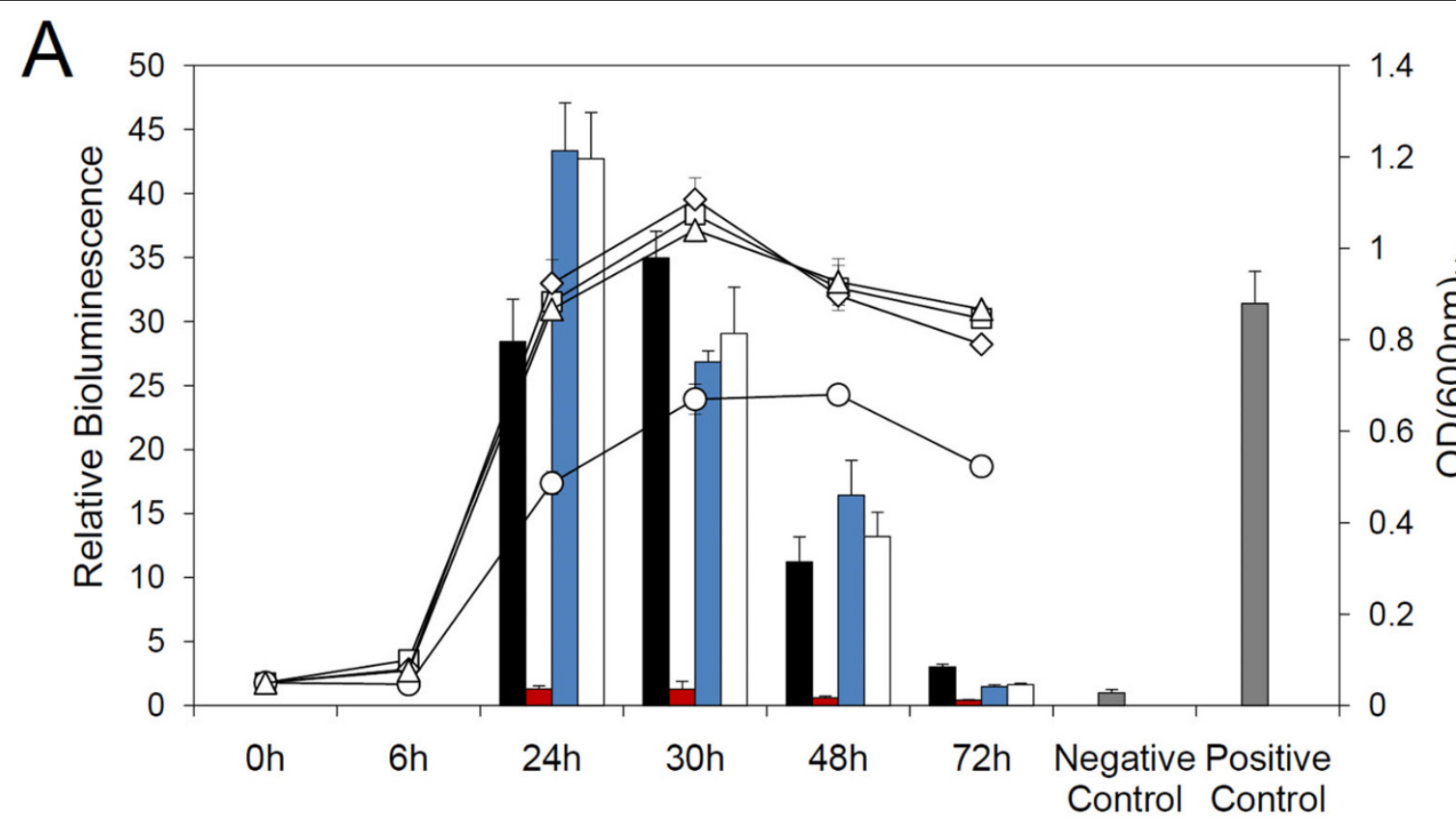

B

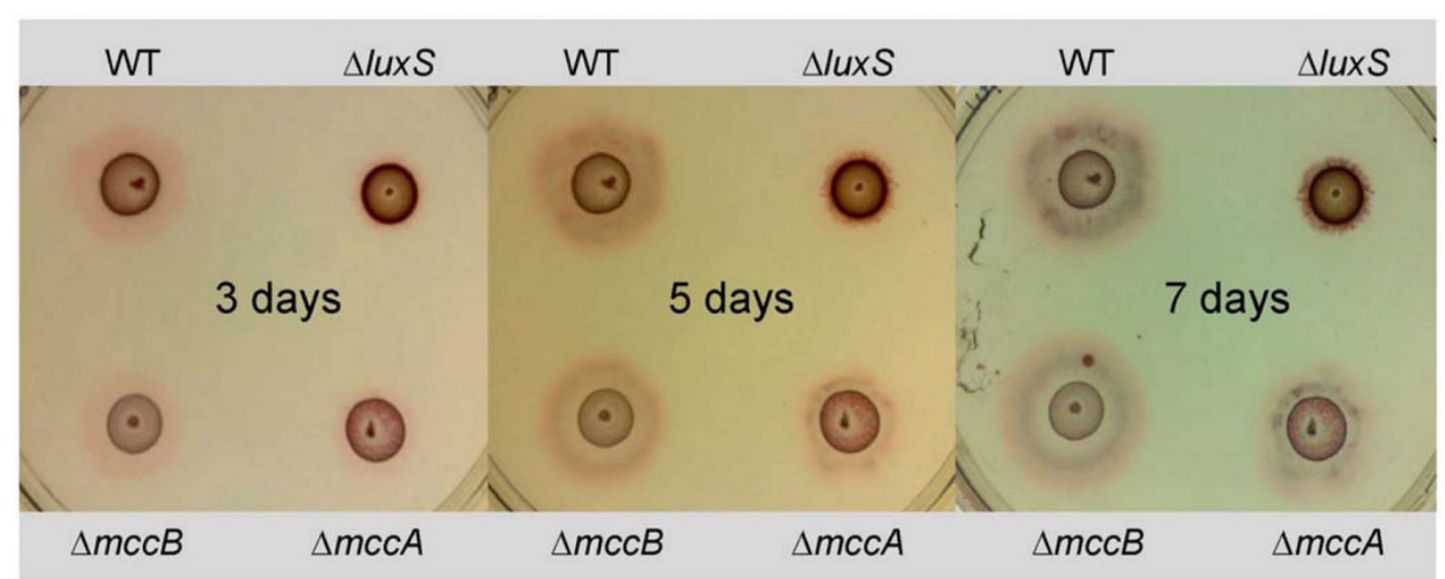

Figure 1 The $\Delta /$ lux $_{\mathrm{Hp}}$ mutant of $H$. pylori strain $\mathrm{J} 99$ lacks Al-2 and is non-motile unlike other mutants deficient in cysteine biosynthesis. (A) Al-2 production in $J 99$ wild-type (black column), $\Delta / u x S_{H p}$ (red column), $\Delta m c c B_{H p}$ (blue column) and $\Delta m c c A_{H p}$ (white column) mutants was measured. Strains were grown in Brucella broth, and aliquots were removed at $24 \mathrm{~h}, 30 \mathrm{~h}, 48 \mathrm{~h}$ and $72 \mathrm{~h}$ to assess the optical density (wild-type, square; $\Delta l u x S_{H p}$, diamond; $\triangle m c c B_{H p}$, circle; $\triangle m c c A_{H p}$, triangle) and the amount of Al-2 in the filtered culture supernatant using the $V$. harveyi bioassay. Al-2 activity is shown as a relative bioluminescence (corrected by $\mathrm{OD}_{600 \mathrm{~nm}}$ of $\mathrm{H}$. pylori) in the presence of $H$. pylori culture supernatants over the negative control (Brucella broth alone). A diluted in vitro synthesised Al-2 sample was utilised as a qualitative positive control [8]. Bioluminescence induced by wild-type, $\triangle m c c B_{H p}$, and $\Delta m c c A_{H p}$ strains was significantly greater than that induced by the $\Delta / u x S_{H p}$ mutant, as determined by paired Student's t-test $(p<0.001)$. The lines represent the growth $(\mathrm{OD}$, righthand axis) and the bars represent the Al-2 activity (bioluminescence, lefthand axis). (B) $5 \mu \mathrm{l}$ of liquid culture (24 h) of the wild-type, $\Delta / u x S_{H p}, \triangle m c c B_{H p}$ and $\triangle m c c A_{H p}$ mutants was seeded on each quarter of a soft agar plate. After 3,5 and 7 days of incubation, the motility halo of each strain was recorded using a digital camera. All experiments were done in triplicate: a representative experiment is shown and the mean results are presented in the text.

and $\Delta f l h B_{\mathrm{Hp}}$ mutants showed non-motile phenotypes (Figure. 2A).

To examine whether AI-2 can influence the motility of $H$. pylori, we assessed the motility of the wild-type, $\Delta l u x S_{\mathrm{Hp}}$ and $\Delta f l h B$ mutants on AI-2 supplemented plates (ASP). The ASP was prepared using $0.4 \%$ soft agar containing in vitro synthesised AI-2 $(0.25 \% \mathrm{v} / \mathrm{v})$.
The buffer control plate (BCP) was also produced using $0.4 \%$ soft agar into which was added the buffer control solution $(0.25 \% \mathrm{v} / \mathrm{v})$ produced in parallel to in vitro AI-2 synthesis (buffer containing no AI-2). After 5 days of incubation, the halo size of the wild-type on ASP increased by $11.2 \pm 0.7 \mathrm{~mm}, n=4$, compared with a $5.4 \pm 0.2 \mathrm{~mm}, n=4$ increase on the non-supplemented 


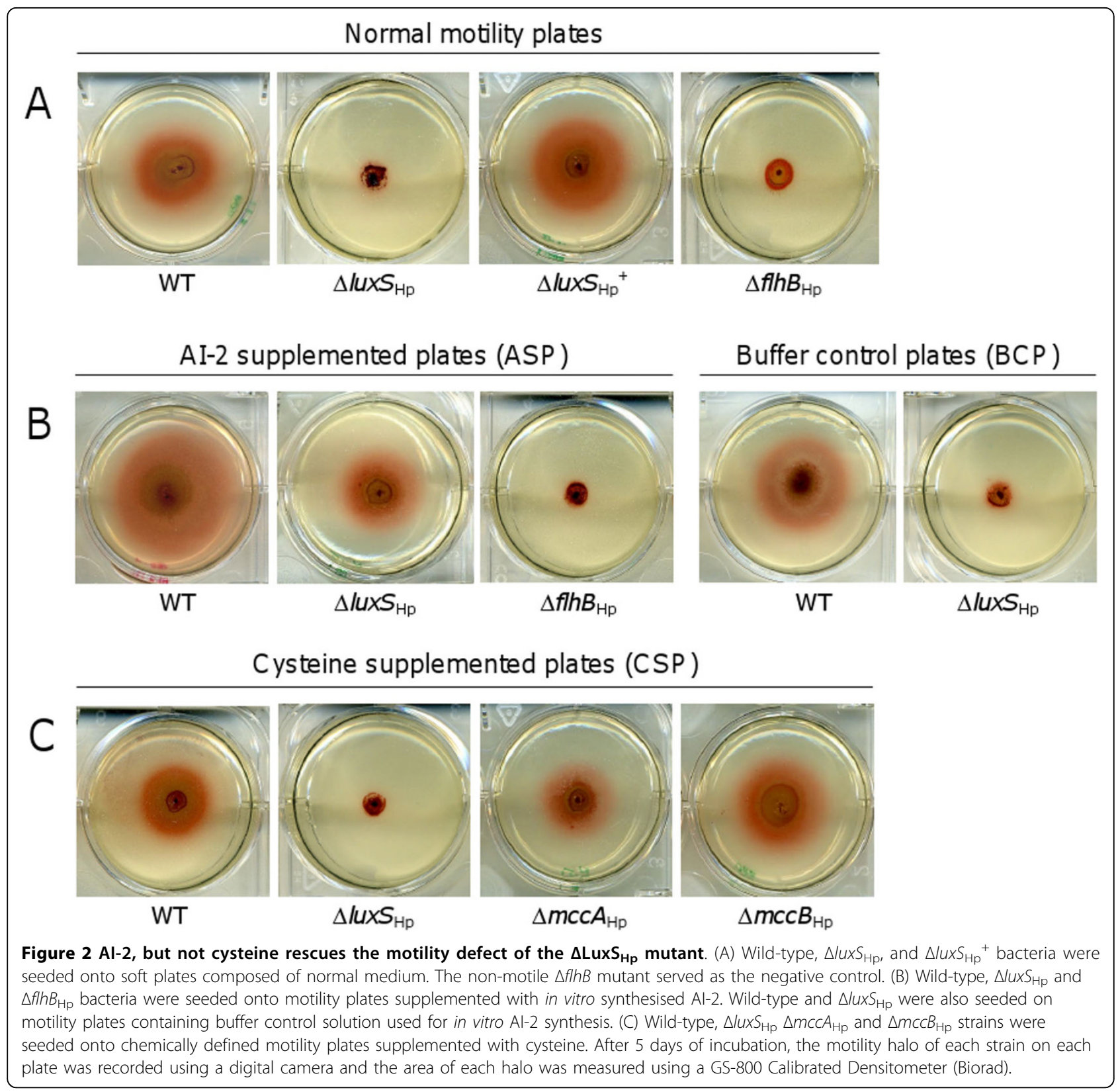

plate (compare Figure. 2A or the right panel of Figure. $2 \mathrm{~B}$ with the left panel of Figure. 2B). Whilst the $\Delta l u x S_{\mathrm{Hp}}$ mutant was non-motile on the $\mathrm{BCP}$, the halo increased by $4.6 \pm 0.4 \mathrm{~mm}, n=4$ on ASP (Figure $2 \mathrm{~B}$ ). The control strain $\Delta f l h B_{\mathrm{Hp}}$ mutant remained non-motile on the ASP (Figure. 2B).

Having established an influence on motility for one of the chemicals reliant on $\mathrm{LuxS}_{\mathrm{Hp}}$ function (AI-2), we sought to establish whether another (cysteine) would have a similar influence. Our previous studies revealed that exogenous cysteine rescues growth defects of mutants unable to complete cysteine biosynthesis via the RTSP of $H$. pylori $\left(\Delta l u x S_{\mathrm{Hp}}, \Delta m c c A_{\mathrm{Hp}}\right.$ and $\Delta m c c B_{\mathrm{Hp}}$ mutants) in chemically defined broth [15]. Chemical complementation of motility was thus performed using chemically defined plates supplemented with $1.0 \mathrm{mM}$ cysteine. Methionine was added to these plates as the sulphur source since all known $H$. pylori strains are methionine auxotrophs. After 5 days of incubation, wild-type $H$. pylori and $\triangle m c c A_{\mathrm{Hp}}$ and $\triangle m c c B_{\mathrm{Hp}}$ mutants formed motility halos of $4.9 \pm 0.3 \mathrm{~mm}, n=4$; $3.6 \pm$ $0.6 \mathrm{~mm}, n=4$; and $4.3 \pm 0.9 \mathrm{~mm}, \mathrm{n}=4$ increases in diameter, respectively. The $\Delta l u x S_{\mathrm{Hp}}$ mutant remained non-motile (Figure. 2C).

Taken together, these data indicate that the motility defect of the $\Delta l u x S_{\mathrm{Hp}}$ mutant was restored either 
genetically or chemically with AI-2, but not with exogenous cysteine. This suggests that $l u x S$ and AI-2 play a role in enhancing bacterial motility, rather than an intact cysteine biosynthesis pathway, implying a likely role of $l u x S_{\mathrm{Hp}}$ in signalling.

\section{$\Delta \mathrm{LuxS}_{\mathrm{Hp}}$ mutants have altered flagella morphology and motility patterns}

Motility plates effectively indicate motility phenotypes of the population, but do not give any indication of the structure of the motility organelles (flagella), or the motility pattern of individual cells. To characterise the phenotypes underlying the decreased ability of the $\Delta l u x S_{\mathrm{Hp}}$ mutant to swarm in soft agar, we examined motility of individual bacterial cells using phase-contrast microscopy and also the flagellar morphology of the cells using electron microscopy. Cells tested included wild-type, $\Delta l u x S_{\mathrm{Hp}}$ and $\Delta l u x S_{\mathrm{Hp}}{ }^{+}$, all grown in the presence and absence of DPD and cysteine. All cells were grown in co-culture with human gastric adenocarcinoma (AGS) cells for $24 \mathrm{~h}$ before testing, as previous experiments in our laboratory have shown that this gives highly reproducible results in $H$. pylori motility experiments.

Phase-contrast microscopy revealed that $>40 \%$ of wild-type and $\Delta l u x S_{\mathrm{Hp}}{ }^{+}$cells were motile; whereas less than $2 \%$ of $\Delta l u x S_{\mathrm{Hp}}$ cells were motile. When grown with exogenous DPD, motile cells again made up $>40 \%$ of the population for wild-type and $\Delta l u x S_{\mathrm{Hp}}{ }^{+}$cells, but now also made up $>40 \%$ of the population for $\Delta l u x S_{\mathrm{Hp}}$ cells. Cultures of the $\Delta l u x S_{\mathrm{Hp}}$ grown with exogenous cysteine consistently contained less than $2 \%$ motile cells. To exclude the possibility that the restoration of motility of $\Delta l u x S_{\mathrm{Hp}}$ cells was due to an effect of DPD on AGS cells rather than on $H$. pylori, we set up a control sample in which the wild-type and $\Delta l u x S_{\mathrm{Hp}}$ mutant were co-cultured individually with AGS cells that had been treated with DPD overnight. DPD was washed off with the media before co-culturing. As expected, both wildtype and $\Delta l u x S_{\mathrm{Hp}}$ cells in these control cultures showed very similar motility phenotypes to those co-cultured with normal AGS cells, indicating that DPD is a functional signalling molecule to $H$. pylori cells rather than it working through affecting eukaryotic cells. Moreover, the approximate speed of motile $\Delta l u x S_{\mathrm{Hp}}$ cells was visibly lower compared to the wild-type, $\Delta l u x S^{+}$and all cell samples plus DPD.

Electron microscopic images (Figure. 3) showed that all samples tested (wild-type, $\Delta l u x S_{\mathrm{Hp}}$ and $\Delta l u x S_{\mathrm{Hp}}{ }^{+}$, grown in the presence or absence of DPD) produced a flagellar filament of some kind in the majority of bacterial cells, but those of the $\Delta l u x S_{\mathrm{Hp}}$ strain were consistently short and usually fewer in number. In our experiments, nearly all of the wild-type cells tested had flagella $(95 \% \pm 3 \%, \mathrm{n}=3)$ and most of these had multiple flagella, which were usually at one pole and typically $3-4$ in number $(90 \% \pm 3 \%, n=3)$ (Figure. 3A). In contrast, fewer $\Delta l u x S_{\mathrm{Hp}}$ cells tested had flagella $(70 \% \pm 5 \%$, $\mathrm{n}=3)$ and these were typically shorter and also fewer in number $(30 \% \pm 5 \%, \mathrm{n}=3$ of cells had only one or two short flagella (Figure. 3B)). The complemented $\Delta l u x S_{\mathrm{Hp}}{ }^{+}$ cells were similar to wild-type, with nearly all cells possessing 3-4 normal long flagella at least one pole $(95 \% \pm$ $3 \%, \mathrm{n}=3$ ) (Figure. 3C). Addition of DPD to $\Delta l u x S_{\mathrm{Hp}}$ cells also converted them to a wild-type morphology, with the vast majority producing 3-4 wild-type length flagella usually present at a single pole $(95 \% \pm 3 \%$, $\mathrm{n}=3$ ) (Figure. 3E). Addition of DPD to wild-type cells had little significant effect with nearly all remaining flagellate as before $(95 \% \pm 3 \%, \mathrm{n}=3)$ although more cells were seen with a flagellum at both poles (Figure. 3D). Addition of DPD to the $\Delta l u x S_{\mathrm{Hp}}{ }^{+}$cells had a similar effect, with more cells with flagella at both poles (Figure. 3F).

\section{Mutation of luxS $\mathrm{S}_{\mathrm{Hp}}$ resulted in the decreased production of flagellar proteins FlaA and FlgE}

The reduced number and length of flagella in $\Delta l u x S_{\mathrm{Hp}}$ cells observed by electron microscopy could emanate from a number of different changes in the proteome. As previous work had suggested possible involvement of major flagella proteins, we investigated these first by immunoblotting whole cell lysates. Cell lysates were adjusted so that protein from equivalent numbers of bacteria was loaded (see Materials and Methods), and probed with anti-flagellin (FlaA and FlaB) and anti-FlgE (hook protein) antiserum (Figure. 4). In practice, FlaB levels were very similar between all wild-type and mutant strains and were not shown to vary in our subsequent transcription analysis. Our main aim here was to compare ratios of flagella proteins between wild-types and mutants, so we expressed results of other flagella proteins (FlaA and FlgE) relative to FlaB levels within each strain. H. pylori wild-type 17874, and derived mutants $(\triangle f l a A$ and $\triangle f l g E)$ were used as positive and negative controls, respectively. In our experiments, four repetitions were included, when the reflective density (RD) of each protein band was measured using Quantity One 4.6.5 software (Biorad).

We found that all strains tested produced FlaB at approximately the same level (Figure. 4). The reflective density of the FlaB bands of the wild-type, $\Delta l u x S_{\mathrm{Hp}}$ mutant and the complemented $\Delta l u x S_{\mathrm{Hp}^{+}}{ }^{+}$mutant were (means $\pm \mathrm{SD}$ ) $0.210 \pm 2.0 \mathrm{E}-03 \mathrm{RD}, \mathrm{n}=4$; $0.204 \pm 5.8 \mathrm{E}-$ 04 $\mathrm{RD}, \mathrm{n}=4$; and $0.207 \pm 5.8 \mathrm{E}-04 \mathrm{RD}, \mathrm{n}=4$, respectively. We expressed all other results (FlaA and FlgE) relative to FlaB in each strain. Mutagenesis of $\operatorname{LuxS}_{\mathrm{Hp}}$ reduced the expression of FlaA relative to FlaB (from 


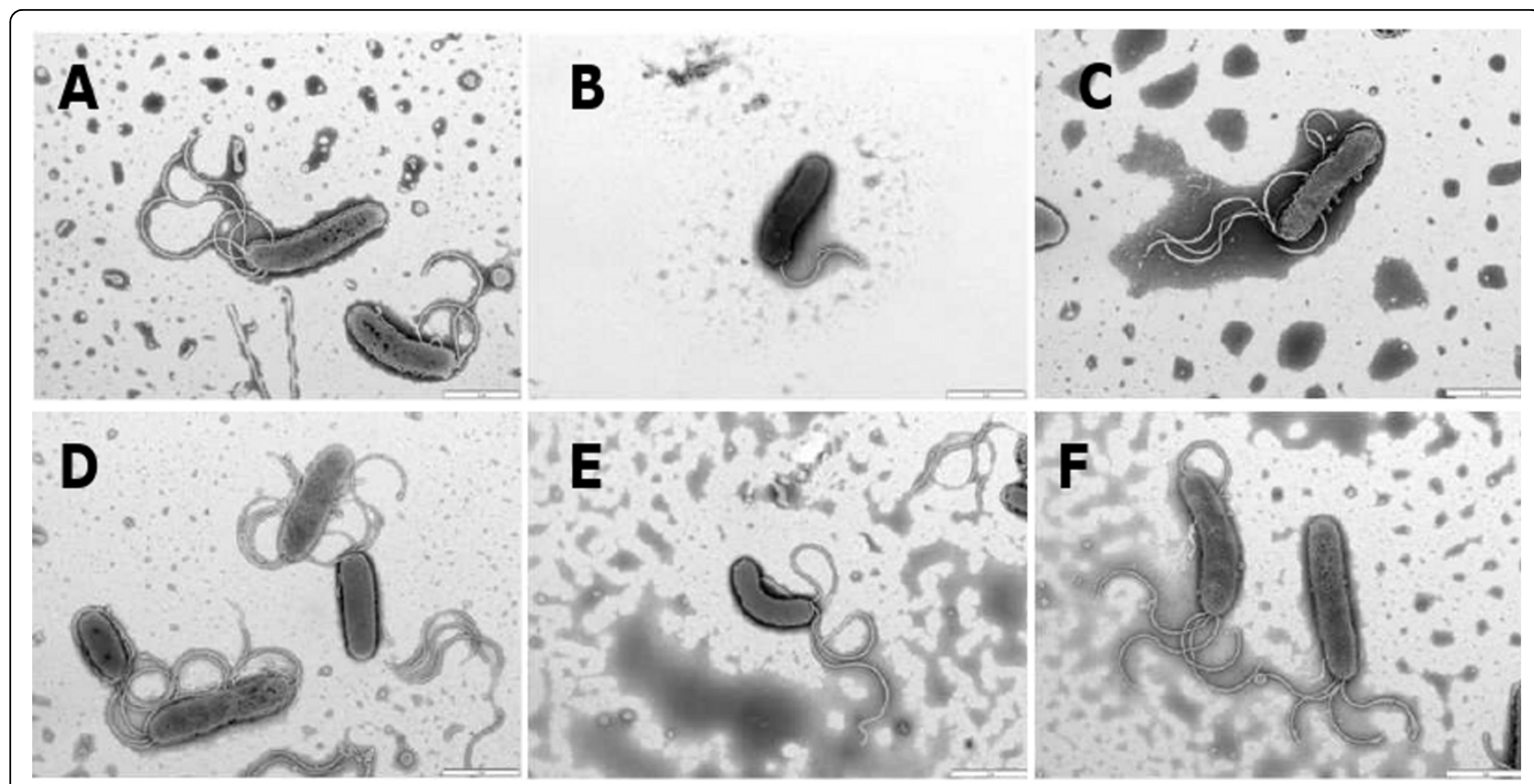

Figure 3 luxS $\mathrm{Hp}_{\mathrm{Hp}}$ /DPD modulates flagellar morphogenesis. H. pylori cells were co-cultured with AGS cells. Cells were stained with $0.5 \%$ photungstate (PTA). Scale bars represent $2 \mu \mathrm{m}$. (A) wild-type, (B) $\Delta / u x S_{H p},(C) \Delta / u x S_{H p}{ }^{+}$, (D) wild-type with DPD, (E) $\Delta / u x S_{H p}$ with DPD and (F) $\triangle \mathrm{uxS} \mathrm{Hp}^{+}$with DPD. DPD was added after $10 \mathrm{~h}$ of incubation and once again after $18 \mathrm{~h}$ of incubation during co-cultures.

mean 1.60 in the wild-type to 1.23 in the $\Delta l u x S_{\mathrm{Hp}}$ mutant, $p<0.01$ ), and complementation increased the ratio back to wild-type levels (mean 1.70 in the $\Delta l u x S_{\mathrm{Hp}}{ }^{+}$mutant, $p<0.01$ compared with the $\Delta l u x S_{\mathrm{Hp}}$ mutant). Next, we examined FlgE expression, and a similar trend was found (wild-type FlgE:FlaB ratio mean 0.74; $\Delta l u x S_{\mathrm{Hp}}$ mutant 0.51; complemented $\Delta l u x S_{\mathrm{Hp}}{ }^{+}$ mutant $0.77 ; p<0.01$ for differences between $\Delta l u x S_{\mathrm{Hp}}$ mutant and wild-type and complemented stains). These data show that FlaA and FlgE synthesis was reduced relative to FlaB in the $\Delta l u x S_{\mathrm{Hp}}$ mutant and these changes were restored by genetic complementation.

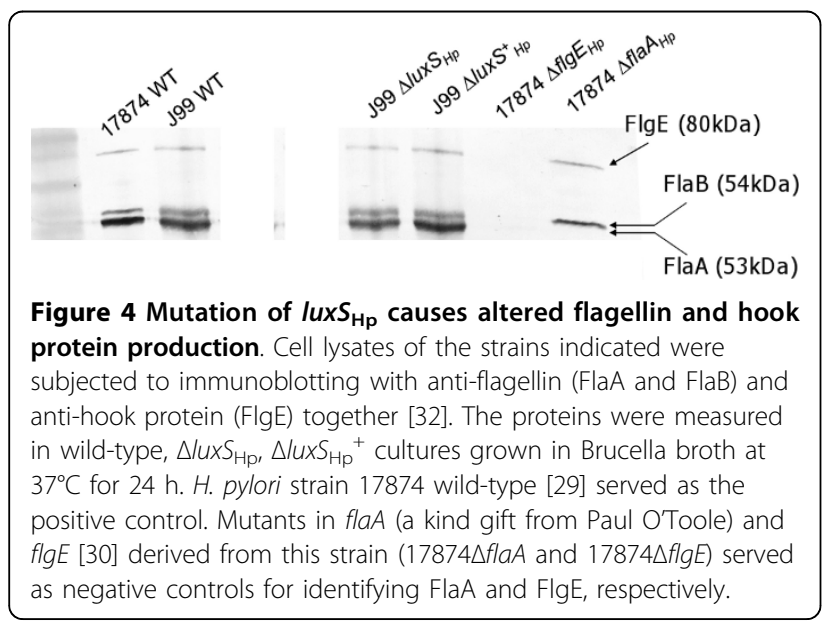

\section{Al-2 regulates the transcription of flagellar genes}

Previous reports have provided evidence that $l u x S_{\mathrm{Hp}^{-}}$ dependent QS may occur to modulate motility via transcriptional regulation of flaA or flhA [20]. We utilised quantitative RT-PCR (qRT-PCR) to screen for alterations in transcription of these and other genes involved in flagellar assembly to extend our understanding of the regulatory mechanisms that might be involved. To exclude an effect of cysteine biosynthesis, exogenous addition of cysteine was also undertaken. The concentration of cysteine was non-limiting to $H$. pylori growth. $16 S$ rRNA transcription was used for normalization and ure $A$ served as a non-flagella linked gene control (Figure. 5D).

The flagellar genes tested included several from different regulatory hierarchy positions in flagellar synthesis [33]: class 1 genes flhA (encodes flagellar regulator component), mot $A$ and $\operatorname{mot} B$ (encode flagellar motor proteins); class 2 genes $f l a B$ (encodes hook-proximal minor flagellin) and $f l g E$ (enodes flagellar hook protein); and class 3 gene flaA (encodes major flagellin). fliI (encodes membrane-associated export ATPase of the flagellar basal body) was also examined (Figure. 5).

For class 1 genes tested, flhA showed a consistent pattern of 1.75 fold reduced transcription $(p<0.001)$, and both $\operatorname{mot} A$ and $\operatorname{mot} B$ showed a consistent pattern of 2 fold $(p<0.001)$ reduced transcription in the $\Delta l u x S_{\mathrm{Hp}}$ mutant compared to the wild-type (Figure. 5A). For class 2 genes tested, flgE was 1.5 fold $(p<0.001)$ 


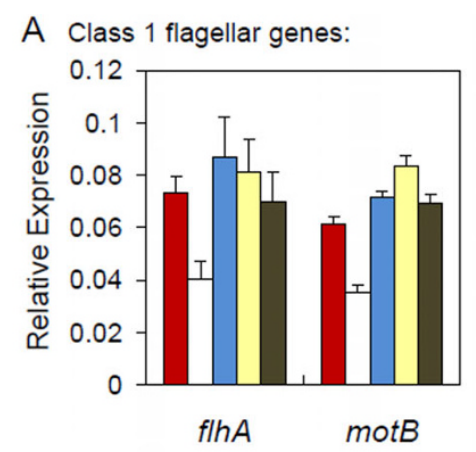

C The flagellar basal body gene:

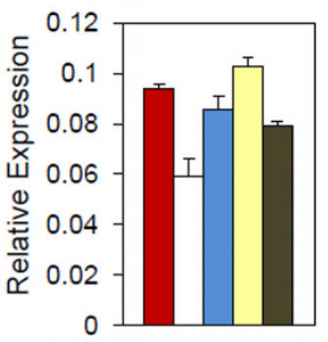

flil

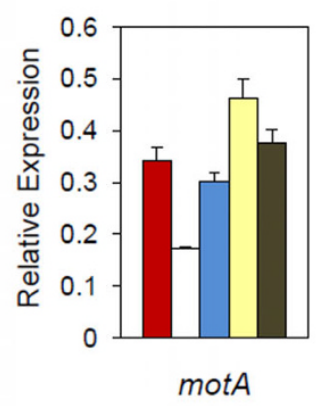

D Non-flagella gene control:

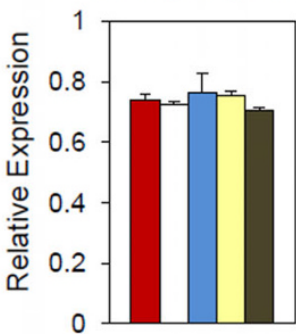

ure $A$
$\mathrm{B}$ Class 2 and 3 flagellar genes:
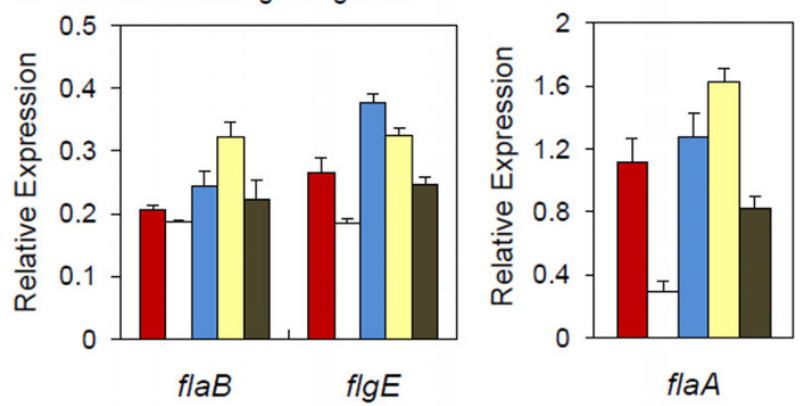

E

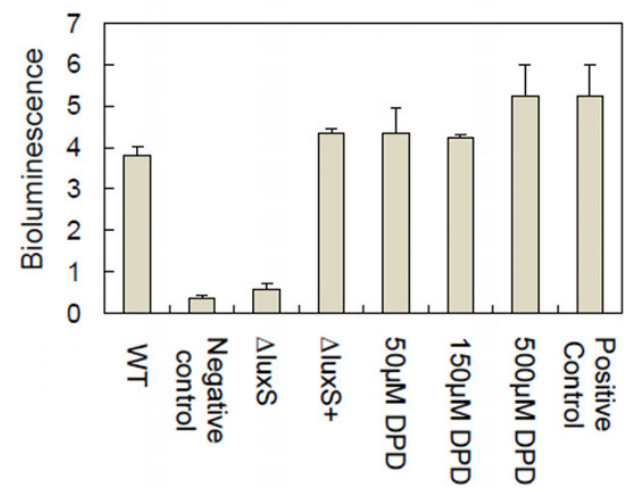

Figure 5 lux $S_{\mathrm{Hp}} / \mathrm{DPD}$ modulates $\boldsymbol{H}$. pylori flagellar gene transcription. Transcript levels of (A) flhA, motA, motB; (B) flaB, flgE, flaA; (C) flil were determined by qRT-PCR normalised to the levels of the $16 \mathrm{~S}$ rRNA gene. (D) Relative expression of ureA was utilised as a non-flagella gene control. The $Y$ axis shows the relative transcriptional level of each gene in each strain normalised to the level of the same gene in the strain control (which is $J 99$ wild-type in every case). Values are mean activities of triplicate RNA samples of each strain. Transcript levels were measured in wild-type and $\triangle / u x S_{H p}$ cultures grown with or without DPD $(150 \mu \mathrm{M})$ and in $\triangle / u x S_{\mathrm{Hp}}{ }^{+}$cultures grown without DPD. (E) Al-2 activity (using the previously-described $V$. harveyi BB170 bioluminescence assay [4]) in DPD solution (at concentrations of $50 \mu \mathrm{M}, 150 \mu \mathrm{M}$ or $500 \mu \mathrm{M}$ ) and in cell free culture supernatant $\left(24 \mathrm{~h}\right.$ ) of $\mathrm{H}$. pylori wild-type, $\Delta / \mathrm{ux} \mathrm{SHp}_{\mathrm{H}}$ and $\Delta / \mathrm{ux} \mathrm{S}_{\mathrm{Hp}}{ }^{+}$strains grown in the Brucella broth (starting $\mathrm{OD}_{600 \mathrm{~nm}}$ of 0.05 ). Negative control is Brucella broth alone. A diluted in vitro synthesised Al-2 sample was utilised as a qualitative positive control [8]. Error bars indicate standard deviation.

down-regulated in the $\Delta l u x S_{\mathrm{Hp}}$ mutant; while flaB did not exhibit any significant change. flaA was the only class 3 gene tested, which was 3.5 fold $(p<0.001)$ down-regulated in the $\Delta l u x S_{\mathrm{Hp}}$ mutant compared to the wild-type (Figure. 5B). Additionally, the transcript of fliI was also significantly $(1.5$ fold, $p<0.001)$ decreased in the mutant (Figure. 5C).

The reduced transcription of $f l h A, \operatorname{mot} A, \operatorname{mot} B, f l g E$, flaA and fliI was restored genetically by the complementation of the mutant with the wild-type $\operatorname{lux} S_{\mathrm{Hp}}$ gene. Also, $150 \mu \mathrm{M}$ DPD was sufficient to restore the transcription of these genes in the $\Delta l u x S_{\mathrm{Hp}}$ mutant to levels similar to the wild-type (Figure. 5E). Although Figure 5E shows that $50 \mu \mathrm{M}$ and $150 \mu \mathrm{M}$ DPD induced almost the same level of bioluminescence as the wild-type, we chose to use $150 \mu \mathrm{M}$ DPD in the complementation experiment because this concentration was shown to be more reproducible (it has the smaller error bar). In wild-type cells, addition of DPD markedly increased transcription of $m o t A, \operatorname{mot} B, f l a A$ and $f l a B$, whilst flhA, $f l g E$ and $f l i$ only showed a marginal increase. Exogenous addition of cysteine to the $\Delta l u x S_{\mathrm{Hp}}$ mutant did not significantly increase transcription of any of the genes studied; suggesting that addition of cysteine was not able to restore the transcription of flagellar genes (data not shown). Consistent with the analysis of protein levels, these RT-PCR data indicate that $\operatorname{lux} S_{\mathrm{Hp}}$ disruption has a greater effect upon transcription of $f l a A$ than of flaB. Taken together, these data suggest that the effect of LuxS in cysteine metabolism does not regulate expression of flagellar genes, and that the effects on flagellar gene transcription are likely through AI-2 production.

\section{Discussion}

The function of $\operatorname{lux} S_{\mathrm{Hp}}$ is controversial due to putative roles both in signalling and metabolism. Disruption of cysteine biosynthesis by independent mutations that had 
no influence on AI-2 production did not alter motility. In contrast, the motility defect of a $\Delta l u x S_{\mathrm{Hp}}$ mutant of H. pylori was genetically complemented by $\operatorname{lux} S_{\mathrm{Hp}}$, or chemically complemented by the addition of exogenous AI-2 but not by exogenous cysteine. The processes underlying the loss of motility of the $\Delta l u x S_{\mathrm{Hp}}$ mutant were manifested by fewer and shorter flagella that presumably derived from the altered flagella protein production and the modulated expression of a number of genes linked with flagella assembly and function.

Previous studies have shown that mutations of $\operatorname{lux} S_{\mathrm{Hp}}$ in H. pylori diminished motility on soft agar. The altered motility phenotype was restored completely by genetic complementation with $l u x S_{\mathrm{Hp}}$ or significantly restored by metabolic complementation with wild-type CFS [18-20]. In contrast to our study, in Osaki et al. and Rader et al.'s studies complementation of $\operatorname{lux} S_{\mathrm{Hp}}$ was performed by placing $\operatorname{lux} S_{\mathrm{Hp}}$ at a second site in the chromosome rather than at the original locus $[19,20]$. Like these previous reports, our study shows that abolished motility of $\mathrm{J} 99$ $\Delta l u x S_{\mathrm{Hp}}$ mutation was restored entirely by complementation with the $\operatorname{lux} S_{\mathrm{Hp}}$ gene and significantly by in vitro synthesised AI-2. The previous studies, with complete complementation of motility with $\operatorname{lux} S_{\mathrm{Hp}}$ through insertion at a new chromosomal locus, argue against polar effects of $l u x S_{\mathrm{Hp}}$ mutagenesis on other genes which influence motility. Our study, with complementation with $l u x S_{\mathrm{Hp}}$ through creating a revertant results in similar levels of LuxS $S_{\mathrm{Hp}}$ to wild-type and thus better shows that the phenotypes attributed to the mutant were not due to secondary mutations elsewhere in the chromosome.

Furthermore, having demonstrated that $\mathrm{MccA}_{\mathrm{Hp}}$ and $\mathrm{MccB}_{\mathrm{Hp}}$ function consecutively to convert the product of $\operatorname{LuxS}_{\mathrm{Hp}}$ (homocysteine) into cysteine as part of the RTSP [15], we reasoned that inactivation of any of these three enzymes would have a similar influence upon cysteine biosynthesis, whilst only the $\Delta l u x S_{\mathrm{Hp}}$ mutant would be devoid of AI-2. Thus, if the reduced motility of the $\Delta l u x S_{\mathrm{Hp}}$ mutant derived from disrupted cysteine biosynthesis, mutants in $m c c A_{\mathrm{Hp}}$ and $m c c B_{\mathrm{Hp}}$ would have a similar motility defect. Therefore, we performed an experiment to exclude the possibility that the effect on motility was due to non-specific secondary metabolic effects of LuxS $\mathrm{Hp}_{\mathrm{Hp}}$. To do this, wild-type, $\Delta l u x S_{\mathrm{Hp}}$, $\triangle m c c A_{\mathrm{Hp}}$ and $\Delta m c c B_{\mathrm{Hp}}$ strains were inoculated on the same motility plate, allowing the production of AI-2 and the biosynthesis of cysteine to be isolated from each other. As expected, only the $\Delta l u x S_{\mathrm{Hp}}$ mutant was nonmotile. This, for the first time, suggests that motility of H. pylori cannot be affected by disrupting the cysteine provision pathway, but can be blocked by the loss of $\operatorname{lux} S_{\mathrm{Hp}}$ itself. By using a chemically defined medium, we confirmed the provision of cysteine had no effect on motility of $H$. pylori.
Earlier publications have suggested that AI-2 may not act as a signal in some bacteria but instead may simply be a by-product of the important AMC pathway [9]. In support of this, in some bacteria, production of AI-2 does appear to be associated with metabolic rather than regulatory phenomena [34]. However, data from our motility bioassays using both motility plates and microscopy demonstrate that in H. pylori AI-2 (or DPD) controls motility. In our experiments, the shorter flagella observed in the mutant could result from the observed alteration in the FlaA:FlaB ratio as previously described $[35,36]$. However, proving this would require extensive immuno-EM analysis with anti-FlaA and anti-FlaB antisera, which is beyond the scope of this work. As flaA has been confirmed to be essential for motility in $H$. pylori while $f l a B$ is a structural subunit of the flagellar filament which increases motility $[35,36]$, the change of the ratio between flagellins FlaA and FlaB may be one factor resulting in the abolished motility of the $\Delta l u x S_{\mathrm{Hp}}$ mutant. Also, $\mathrm{LuxS}_{\mathrm{Hp}} / \mathrm{AI}-2$ appears to affect the position of flagella, suggesting that $\mathrm{LuxS}_{\mathrm{Hp}} / \mathrm{AI}-2$ may affect genes involved in the formation of flagella at the cell poles.

The reduced expression of flagellar motor genes (motA and $m o t B$ ) which control flagellar rotation may be a further factor contributing to slower motility of the $\Delta l u x S_{\mathrm{Hp}}$ mutant although it could also be caused by the lower flagellar number requiring fewer motor units to encircle each flagellar base. Thus it is likely that the flagella in the $\Delta l u x S_{\mathrm{Hp}}$ strain are too short and too few to form effective flagellar propellers to produce Helicobacter movement. This is in contrast to a previous report where truncated flagella were only reported in G27 strains that also lacked one of the transcriptional regulators $\left(\sigma^{28}, f l g S\right.$ or $\left.f l g M\right)$ and where wild-type length flagella were reported for the $\Delta l u x S_{\mathrm{Hp}}$ mutant alone [20]. However, surprisingly in that report, the addition of DPD to the double mutants lengthened the flagellar filaments.

Mutants defective in $f l h A$ were previously described as being defective in flagellar apparatus assembly and in motility. Recently Rust and coworkers (2009) reported that the anti-sigma factor for $\sigma^{28}$, FlgM, interacts with FlhA at the base of the Helicobacter flagellum and this interaction modulates the expression of flagellar genes by $\sigma^{28}$ [37]. The decrease in $f l h A$ expression, seen in our $\Delta l u x S_{\mathrm{Hp}}$ mutant could explain the change in flagellar length but not via a FlgM-dependent pathway as seen by Rader et al. [20], as Rust and coworkers report that FlgM levels were wild-type in a $\triangle f l h A$ mutant in Helicobacter strains N6 and 88-3887 [37].

Both Rust and co-workers [37] and Neihus and coworkers [33] show that FlaB is not regulated by the same regulatory pathway as FlaA, and as FlaB levels in 
our $\Delta l u x S_{\mathrm{Hp}}$ mutant concur with this, the short flagella we observe in the $\Delta l u x S_{\mathrm{Hp}}$ mutant are likely to be predominantly composed of FlaB (normally hook-proximal) flagellins. These may be extended, to give functional length propellers by synthesis and assembly of FlaA in wild-type filaments and in filaments from $l u x S_{\mathrm{Hp}}$-complemented $\Delta l u x S_{\mathrm{Hp}}{ }^{+}$bacteria or $\Delta l u x S_{\mathrm{Hp}}$ bacteria+DPD which have longer flagella.

$\mathrm{FlaB}$ and FlgE are both part of the regulon that is controlled by the FlgS/FlgR two component system and the sigma factor $\sigma^{54}$ (RpoN) [33]. Interestingly, though no significant change in $\mathrm{FlaB}$ was found, FlgE production as well as its gene expression was affected by loss of LuxS/ AI-2. This suggests that luxS inactivation might affect transcription of the same class of flagellar genes differently. One possibility is that the FlgR/FlgS- $\sigma^{54}$ regulatory complex might have different effects on the same class of genes when affected by loss of LuxS; another possibility is that there may be additional regulation from the other regulator genes, for example $f l h F$.

Flagellar assembly uses a secretion apparatus similar to type III secretion systems. This is dependent upon export chaperones that protect and transport structural subunits using the membrane-associated export ATPase, FliI $[38,39]$. Therefore, the decreased transcription of fliI might be another factor in blocking motility via shortened filament length in the $\Delta l u x S_{\mathrm{Hp}}$ mutant as Helicobacter fliI mutants are non-motile and synthesise reduced amounts of flagellin (FlaA, FlaB) and hook protein (FlgE) subunits [38].

In our experiments, the motility defect, down-regulated flagellar gene expression and reduced synthesis of flagellar proteins in the $\Delta l u x S_{\mathrm{Hp}}$ mutant were due to loss of AI-2 only, and not to the metabolic effect of $\operatorname{lux} S_{\mathrm{Hp}}$ on biosynthesis of cysteine. These results suggest that LuxS/AI-2 is likely to be a functional signalling system contributing to control motility in H. pylori. However, it is still uncertain whether AI-2 functions as a true QS signal in $H$. pylori, in part because there are no genes encoding proteins that can be confidently identified as components of an AI-2 sensory and regulatory apparatus in $H$. pylori $[13,40]$. Also, we cannot exclude the possibility that AI-2 acts through other undefined effects and not as a signalling molecule, although as it is known to have similar effects through signalling in other bacteria, this appears unlikely.

Campylobacter jejuni also possesses a luxS homologue and produces AI-2. Inactivation of $\operatorname{luxS}$ in a C. jejuni strain (81-176) also resulted in reduced motility and affected transcription of some genes [41]. However, despite its effect on signalling, AI-2 does not function as a QS molecule in C. jejuni (NCTC 11168) during exponential growth in vitro when a high level of AI-2 is produced [42]. Thus, so far there is no good evidence to ascertain whether AI-2 functions as a true QS signal in this species. In $H$. pylori, Lee et al. and Osaki et al. looked at fitness of $\Delta l u x S_{\mathrm{Hp}}$ mutants in vivo using mouse and gerbil models, respectively $[18,19]$. The authors did not favour a QS or even a signalling explanation for the reduced fitness mechanisms but both speculated that it might be caused by metabolic disturbances upon loss of lux $S_{\mathrm{Hp}}[18,19]$. However, it could potentially be explained by reduced signalling leading to reduced motility, and given the ecological niche of $H$. pylori there would be logic to a signalling (perhaps even QS) system increasing motility. For example, we speculate that if a microcolony of $H$. pylori in a particular area of the stomach reached a critical size it would be potentially advantageous for flagellar biogenesis to be enhanced so that highly motile bacteria could disseminate to new regions of the stomach. If this hypothesis was confirmed, it would have important implications for $H$. pylori virulence and for the spread of infection within and between people.

\section{Conclusions}

Our study suggests that as well as being a metabolic enzyme in the reverse transsulphuration pathway, H. pylori LuxS has a second role in regulation of motility by modulating flagellar transcripts and flagellar biosynthesis. This is achieved through production of the signalling molecule AI-2, rather than the metabolic effect of LuxS in cysteine biosynthesis.

List of abbreviations

AMC: activated methyl cycle; AI-2: auto-inducer-2; CFS: cell free supernatant; DPD: 4, 5-dihydroxy-2, 3-pentanedione; QS: quorum sensing; RD: reflective density; RTSP: reverse transsulphuration pathway.

\section{Authors' contributions}

JCA and $\mathrm{KRH}$ contributed to the design and supervision of the study. FS participated in the design of experiments, carried out the study, analysed data and drafted the manuscript. LH and RES contributed to the work of microscopy and flagellar morphology, and wrote the related section of the manuscript. ND contributed to the construction of the $\triangle /$ uxS mutant. JTL and TLC designed and generated the plasmids needed for the construction of the complemented $\triangle$ luxS $S^{+}$mutant. $\mathrm{KRH}, \mathrm{RES}, \mathrm{TLC}, \mathrm{LH}$ and ND gave useful comments to the manuscript. JCA and FS coordinated the manuscript to the final version. All authors read and approved the final manuscript.

\section{Acknowledgements}

We thank Trevor Gray (QMC Histopathology EM Unit) for technical assistance with electron microscopy; Klaus Winzer (University of Nottingham) for kindly providing E. coli strains DH5 $\alpha$ LuxS and DH5 $\alpha$ Pfs; and Paul O'Toole (University College Cork, Ireland) for the generous gift of H. pylori 17874 strains and antibodies against $H$. pylori flagellin and hook protein.

This project was generously supported by the National Institute of Health Research through its funding of the Nottingham Digestive Diseases Centre Biomedical Research Unit. FS was supported by a studentship awarded by Overseas Research Students Awards Scheme (ORSAS) and Nottingham University. LH was supported by grant HFSP RGP57/2005 to RES. The support of the BBSRC to $\mathrm{KH}$ is also gratefully acknowledged.

\section{Author details}

${ }^{1}$ Centre for Biomolecular Sciences, University of Nottingham, University Park, Nottingham NG7 2RD, UK. ${ }^{2}$ Nottingham Digestive Diseases Centre NIHR 
Biomedical Research Unit, School of Clinical Sciences, University of Nottingham and Nottingham University Hospitals NHS Trust, Nottingham NG7 2UH, UK. ${ }^{3}$ Institute of Genetics, School of Biology, Queen's Medical Centre, University of Nottingham NG7 2UH, UK. ${ }^{4}$ Department of Medicine Vanderbilt University School of Medicine, Nashville, TN 037232-2605 and Veterans Affairs Tennessee Valley Healthcare System, Nashville, TN 37212, USA. ${ }^{5}$ School of Molecular Medical Sciences, University of Nottingham, University Park, Nottingham NG7 2RD, UK. ${ }^{6}$ Current Address: Department of Veterinary Medicine, University of Cambridge, Cambridge CB3 OES, UK. ${ }^{7}$ Current Address: Department of Food Sciences, Sutton Bonington Campus, University of Nottingham, Leicestershire LE12 5RD, UK.

Received: 27 January 2010 Accepted: 6 August 2010

Published: 6 August 2010

\section{References}

1. Winzer K, Hardie KR, Williams P: Bacterial cell-to-cell communication: sorry, can't talk now - gone to lunch! Curr Opin Microbiol 2002, 5(2):216-222.

2. Camilli A, Bassler BL: Bacterial small-molecule signaling pathways. Science 2006, 311(5764):1113-1116

3. Vendeville A, Winzer K, Heurlier K, Tang CM, Hardie KR: Making 'sense' of metabolism: autoinducer-2, LuxS and pathogenic bacteria. Nat Rev Microbiol 2005, 3(5):383-396.

4. Bassler BL, Greenberg EP, Stevens AM: Cross-species induction of luminescence in the quorum-sensing bacterium Vibrio harveyi. J Bacteriol 1997, 179(12):4043-4045.

5. Camara M, Hardman A, Williams P, Milton D: Quorum sensing in Vibrio cholerae. Nat Genet 2002, 32(2):217-218.

6. Hardie KR, Heurlier K: Establishing bacterial communities by 'word of mouth': LuxS and autoinducer 2 in biofilm development. Nat Rev Microbiol 2008, 6(8):635-643.

7. Duerre JA, Walker RD: The Biochemistry of Adenosylmethionine. Columbia University Press, New York 1977.

8. Winzer K, Hardie KR, Burgess N, Doherty N, Kirke D, Holden MT, Linforth R, Cornell KA, Taylor AJ, Hill PJ, Williams P: LuxS: its role in central metabolism and the in vitro synthesis of 4-hydroxy-5-methyl-3(2H)furanone. Microbiology 2002, 148(Pt 4):909-922.

9. Winzer $K$, Hardie KR, Williams P: LuxS and autoinducer-2: their contribution to quorum sensing and metabolism in bacteria. Adv Appl Microbiol 2003, 53:291-396.

10. Atherton JC: The pathogenesis of Helicobacter pylori-induced gastroduodenal diseases. Annu Rev Pathol 2006, 1:63-96.

11. Forsyth $\mathrm{MH}$, Cover TL: Intercellular communication in Helicobacter pylori: luxS is essential for the production of an extracellular signaling molecule. Infect Immun 2000, 68(6):3193-3199.

12. Joyce $E A$, Bassler $B L$, Wright $A$ : Evidence for a signaling system in Helicobacter pylori: detection of a luxS-encoded autoinducer. J Bacteriol 2000, 182(13):3638-3643

13. Tomb JF, White $O$, Kerlavage $A R$, Clayton RA, Sutton GG, Fleischmann RD, Ketchum KA, Klenk HP, Gill S, Dougherty BA, Nelson K, Quackenbush J, Zhou L, Kirkness EF, Peterson S, Loftus B, Richardson D, Dodson R Khalak HG, Glodek A, McKenney K, Fitzegerald LM, Lee N, Adams MD, Hickey EK, Berg DE, Gocayne JD, Utterback TR, Peterson JD, Kelley JM, et al: The complete genome sequence of the gastric pathogen Helicobacter pylori. Nature 1997, 388(6642):539-547.

14. Doig $P$, de Jonge BL, Alm RA, Brown ED, Uria-Nickelsen M, Noonan B, Mills SD, Tummino P, Carmel G, Guild BC, Moir DT, Vovis GF, Trust TJ: Helicobacter pylori physiology predicted from genomic comparison of two strains. Microbiol Mol Biol Rev 1999, 63(3):675-707.

15. Doherty NC, Shen F, Halliday NM, Barrett DA, Hardie KR, Winzer K, Atherton JC: In Helicobacter pylori, LuxS is a key enzyme in cysteine provision through a reverse transsulfuration pathway. J Bacterio/ 2010 192(5):1184-1192.

16. Cole SP, Harwood J, Lee R, She R, Guiney DG: Characterization of monospecies biofilm formation by Helicobacter pylori. J Bacteriol 2004 186(10):3124-3132

17. Loh JT, Forsyth $\mathrm{MH}$, Cover TL: Growth phase regulation of flaA expression in Helicobacter pylori is luxS dependent. Infect Immun 2004, 72(9):5506-5510.
18. Lee WK, Ogura K, Loh JT, Cover TL, Berg DE: Quantitative effect of luxS gene inactivation on the fitness of Helicobacter pylori. Appl Environ Microbiol 2006, 72(10):6615-6622

19. Osaki T, Hanawa T, Manzoku T, Fukuda M, Kawakami H, Suzuki H,

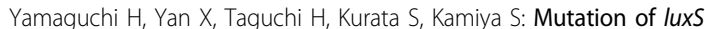
affects motility and infectivity of Helicobacter pylori in gastric mucosa of a Mongolian gerbil model. J Med Microbiol 2006, 55(Pt 11):1477-1485.

20. Rader BA, Campagna SR, Semmelhack MF, Bassler BL, Guillemin K: The quorum-sensing molecule autoinducer 2 regulates motility and flagellar morphogenesis in Helicobacter pylori. J Bacteriol 2007, 189(17):6109-6117.

21. Yanisch-Perron C, Vieira J, Messing J: Improved M13 phage cloning vectors and host strains: nucleotide sequences of the $\mathrm{M} 13 \mathrm{mp} 18$ and pUC19 vectors. Gene 1985, 33(1):103-119.

22. DeKeersmaecker SC, Vanderleyden J: Constraints on detection of autoinducer-2 (Al-2) signalling molecules using Vibrio harveyi as a reporter. Microbiology 2003, 149(Pt 8):1953-1956.

23. Greenberg EP, Hastings JW, Ulitzer S: Induction of luciferase synthesis in Beneckea harveyi by other marine bacteria. Arch Microbiol 1979, 120:87-91.

24. Wand ME, Sockett RE, Evans KJ, Doherty N, Sharp PM, Hardie KR, Winzer K: Helicobacter pylori FlhB function: the FlhB C-terminal homologue HP1575 acts as a "spare part" to permit flagellar export when the HP0770 FlhBCC domain is deleted. J Bacteriol 2006, 188(21):7531-7541.

25. Sambrook J, Fritsch EF, Maniatis T: Molecular cloning: a laboratory manual. Cold Spring Harbor Laboratory Press, Cold Spring Harbor, N Y, 21989.

26. Letley DP, Rhead JL, Twells RJ, Dove B, Atherton JC: Determinants of nontoxicity in the gastric pathogen Helicobacter pylori. J Biol Chem 2003, 278(29):26734-26741.

27. Hall TA: BioEdit: a user-frendly biological sequence alignment editor and analysis program for Windows 95/98/NT//Nuclec Acids Symp. Ser 1999, 41:95-98.

28. Reynolds DJ, Penn CW: Characteristics of Helicobacter pylori growth in a defined medium and determination of its amino acid requirements. Microbiology 1994, 140(Pt 10):2649-2656.

29. Marshall BJ, Royce H, Annear DI, Goodwin CS, Pearman JW, Warren JR, Armstrong JA: Original isolation of Campylobacter pyloridis from human gastric mucosa. Microbios Lett 1984, 25:83-88.

30. O'Toole PW, Kostrzynska M, Trust TJ: Non-motile mutants of Helicobacter pylori and Helicobacter mustelae defective in flagellar hook production. Mol Microbiol 1994, 14(4):691-703.

31. Towbin H, Staehelin T, Gordon J: Electrophoretic transfer of proteins from polyacrylamide gels to nitrocellulose sheets: procedure and some applications. Biotechnology 1992, 24:145-149.

32. Ryan KA, Karim N, Worku M, Penn CW, O'Toole PW: Helicobacter pylori flagellar hook-filament transition is controlled by a Flik functional homolog encoded by the gene HP0906. J Bacteriol 2005, 187(16):5742-5750.

33. Niehus E, Gressmann H, Ye F, Schlapbach R, Dehio M, Dehio C, Stack A, Meyer TF, Suerbaum S, Josenhans C: Genome-wide analysis of transcriptional hierarchy and feedback regulation in the flagellar system of Helicobacter pylori. Mol Microbiol 2004, 52(4):947-961.

34. Doherty N, Holden MT, Qazi SN, Williams P, Winzer K: Functional analysis of luxS in Staphylococcus aureus reveals a role in metabolism but not quorum sensing. J Bacteriol 2006, 188(8):2885-2897.

35. Suerbaum $S$, Josenhans $C$, Labigne A: Cloning and genetic characterization of the Helicobacter pylori and Helicobacter mustelae flaB flagellin genes and construction of $H$. pylori flaA- and flaB-negative mutants by electroporation-mediated allelic exchange. J Bacteriol 1993, 175(11):3278-3288

36. Josenhans C, Labigne A, Suerbaum S: Comparative ultrastructural and functional studies of Helicobacter pylori and Helicobacter mustelae flagellin mutants: both flagellin subunits, FlaA and FlaB, are necessary for full motility in Helicobacter species. J Bacteriol 1995, 177(11):3010-3020.

37. Rust M, Borchert S, Niehus E, Kuehne SA, Gripp E, Bajceta A, McMurry JL, Suerbaum S, Hughes KT, Josenhans C: The Helicobacter pylori anti-sigma factor FlgM is predominantly cytoplasmic and cooperates with the flagellar basal body protein FlhA. J Bacteriol 2009, 191(15):4824-4834

38. Jenks PJ, Foynes S, Ward SJ, Constantinidou C, Penn CW, Wren BW: A flagellar-specific ATPase (Flil) is necessary for flagellar export in Helicobacter pylori. FEMS Microbiol Lett 1997, 152(2):205-211. 
39. Lane MC, OToole PW, Moore SA: Molecular basis of the interaction between the flagellar export proteins Flil and FliH from Helicobacter pylori. J Biol Chem 2006, 281(1):508-517.

40. Rezzonico F, Duffy B: Lack of genomic evidence of Al-2 receptors suggests a non-quorum sensing role for luxS in most bacteria. BMC Microbiol 2008, 8:154.

41. He Y, Frye JG, Strobaugh TP, Chen CY: Analysis of Al-2/LuxS-dependent transcription in Campylobacter jejuni strain 81-176. Foodborne Pathog Dis 2008, 5(4):399-415.

42. Holmes K, Tavender TJ, Winzer K, Wells JM, Hardie KR: Al-2 does not function as a quorum sensing molecule in Campylobacter jejuni during exponential growth in vitro. BMC Microbiol 2009, 9:214.

43. Surette MG, Bassler BL: Quorum sensing in Escherichia coli and Salmonella typhimurium. Proc Natl Acad Sci USA 1998, 95(12):7046-7050.

44. Alm RA, Ling LS, Moir DT, King BL, Brown ED, Doig PC, Smith DR, Noonan B, Guild BC, deJonge BL, Carmel G, Tummino PJ, Caruso A, UriaNickelsen M, Mills DM, Ives C, Gibson R, Merberg D, Mills SD, Jiang Q, Taylor DE, Vovis GF, Trust TJ: Genomic-sequence comparison of two unrelated isolates of the human gastric pathogen Helicobacter pylori. Nature 1999, 397(6715):176-180.

doi:10.1186/1471-2180-10-210

Cite this article as: Shen et al.: In Helicobacter pylori auto-inducer-2, but not LuxS/MccAB catalysed reverse transsulphuration, regulates motility through modulation of flagellar gene transcription. BMC Microbiology 2010 10:210

\section{Submit your next manuscript to BioMed Central and take full advantage of:}

- Convenient online submission

- Thorough peer review

- No space constraints or color figure charges

- Immediate publication on acceptance

- Inclusion in PubMed, CAS, Scopus and Google Scholar

- Research which is freely available for redistribution

Submit your manuscript at www.biomedcentral.com/submit 